Article

\title{
Mechanical Properties and Microstructure of Polyvinyl Alcohol (PVA) Modified Cement Mortar
}

\author{
Jie Fan ${ }^{1}\left(\mathbb{D}\right.$, Gengying $\mathrm{Li}^{2}{ }^{2} * \mathbb{D}$, Sijie Deng ${ }^{1}$ and Zhongkun Wang ${ }^{2}$ \\ 1 School of Civil Engineering, Guizhou Institute of Technology, Guiyang 515063, China; \\ jfan1988@163.com (J.F.); dengsijie1988@163.com (S.D.) \\ 2 College of Water Conservancy and Civil Engineering, South China Agricultural University, \\ Guangzhou 510642, China; 13526578601@163.com \\ * Correspondence: ligengying@scau.edu.cn; Tel.: +86-136-2303-9690
}

Received: 1 May 2019; Accepted: 25 May 2019; Published: 28 May 2019

\begin{abstract}
The mechanical properties of cement mortars with 0 2.0\% (by mass) polyvinyl alcohol (PVA) were experimentally studied, and the effects of PVA incorporation on the hydration products and microstructure of the cement mortar were determined with differential scanning calorimetry (DSC), Fourier transform infrared spectroscopy (FTIR) and scanning electron microscopy (SEM). The results show that the rational content of PVA formed evenly dispersed network-like thin films within the cement matrix, and these network-like films can bridge cracks in the cement matrix and improve the mechanical properties of the cement mortar. Over- incorporation of PVA may result in the formation of large piece polymer films that coat the cement particles, delay the hydration of the cement mortar and adversely affect its performance. The mechanical properties of the cement mortar show a significant increase and then decrease with a change in the PVA incorporation. When the PVA content was $0.6 \%$ and $1.0 \%$, the mortar had the best compressive and flexural strengths, respectively. The compressive strength of the cement mortar increased by $12.15 \%$ for a PVA content of $0.6 \%$, and the flexural strength of the cement mortar increased by $24.83 \%$ for a PVA content of $1.0 \%$.
\end{abstract}

Keywords: polyvinyl alcohol; cement mortar; mechanical properties; microstructure

\section{Introduction}

Cement-based materials behave like typical porous, brittle materials [1-3]. Brittleness makes the cement material easy to crack under the action of external force, which adversely affects the bearing capacity and durability of cement concrete structures. Polymers have good elastic deformation properties, flexibility, acid and alkali corrosion resistance, and good compatibility with cement materials, which can effectively improve the mechanical properties, deformation properties and durability of cement-based materials [4-9]. Therefore, polymers are widely used in repairing roads, bridges, reservoirs and dams and in the bonding engineering of facing materials [10-12].

Polyvinyl alcohol (PVA) is a typical water-soluble nonionic synthetic polymer containing vinyl $[13,14]$. It is harmless and, therefore, considered safe and relatively environmentally friendly [15]. Commercial- grade PVA is usually divided into two categories based on its degree of polymerization and hydrolysis: (1) fully hydrolyzed groups ( $98 \%$ by mole of acetate or more) where the PVA group has been replaced by an alcohol group, and (2) hydrolyzed groups (approximately $87-89 \%$ by mole of acetate group) where the PVA group has been replaced by alcohol groups. Completely hydrolyzed PVA is soluble in hot water and has good film-forming properties (the formed film is insoluble in low-temperature water) and good adhesion properties $[15,16]$. The polyvinyl alcohol after film formation has good deformation properties, toughness, and wear resistance [17,18]. The physical properties of the polyvinyl alcohol film system are very stable. It not only has good heat (no obvious 
change occurs under $140^{\circ} \mathrm{C}$ ), light, and chemical stability but also has excellent gas and water barrier properties (the inside of polyvinyl alcohol can remain dry under high humidity) $[19,20]$. The good physical and chemical properties of polyvinyl alcohol and its formed films enable its wide use in the textile, construction, chemical, and papermaking industries, to name a few.

Owing to the excellent performance as described above, researchers have utilized PVA to modify the mechanical properties of a cement-based material. Singh et al. [21] found that the addition of $3 \%$ of PVA could increase the compressive strength of cement mortar about $12 \%$ due to there exists chemical interaction between PVA and cement hydration. This chemical interaction is effective in improving the interfacial bond between cement hydration and aggregates. Moreover, the chemical products could fill the pores of the cement matrix, resulting in the mechanical properties of the cement matrix increase greatly. Similarly, Kapen et al. [22] demonstrated that the flexural strengths of cement mortar increased by $21 \%$ after loading $1 \%$ PVA when cured in dry condition, respectively. They stated that this improvement was mainly attributed to the formation of PVA film within the cement matrix. Kim et al. [23] found that the improvement in bond strength after loading PVA seems to arise from suppression of the porous interfacial transition zone and inhibition of calcium hydroxide nucleation on the aggregate surface.

Using PVA to enhance the properties of cement composites has attracted extensive attention. However, the previous research mainly focused on the hydration and mechanical properties after loading a mono content of PVA, there is limited information on the effect of PVA with different content on the fresh properties and strength development at the early ages. Moreover, the morphology and microstructure of cement composite with different PVA content lack systematic investigation. The goal of this study was to study the effect of PVA content on the compressive and flexural strength of mortar after 3 days, 7 days, 14 days and 28 days curing, in which PVA/binder weight ratios of $0 \% 0.2 \%$, $0.6 \%, 1.0 \%$, and $2.0 \%$ were adopted. Moreover, the fresh properties and water absorption of mortars were also investigated. Additionally, the morphology and microstructure of mortars after 28 days curing were also analyzed by using differential scanning calorimetry (DSC), Fourier transform infrared spectroscopy (FTIR), and SEM.

\section{The Experiment}

\subsection{Materials and Mix Design}

The cement used was Type P.O 42.5 R Portland cement, produced by Guangdong Tapai Cement Co., Ltd. (Figure 1a). The chemical composition is listed in Table 1. Polyvinyl alcohol (PVA-124 AR) from Xilong-Chem was used. The molecular weight (Mw) was 105,000, and the degree of hydrolysis was $97 \%$ (Figure 1b). The physicochemical characteristics of this polyvinyl alcohol are given in Table 2 . The fine aggregate was China ISO standard sand with the execution criterion of GSB08-1337-2001, from Xiamen ISO Standard Sand Co., Ltd. (Figure 1c). The chemical composition and particle size of standard sand are listed in Table 3. The defoaming agent was produced by Guangdong Defeng Chemical Industry Co., Ltd.

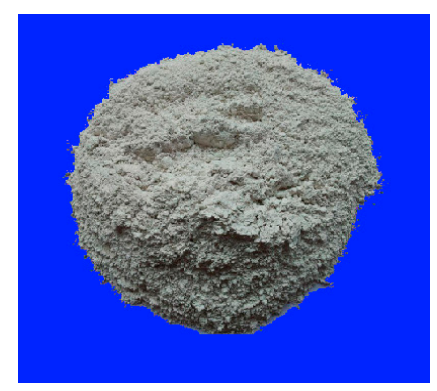

(a)

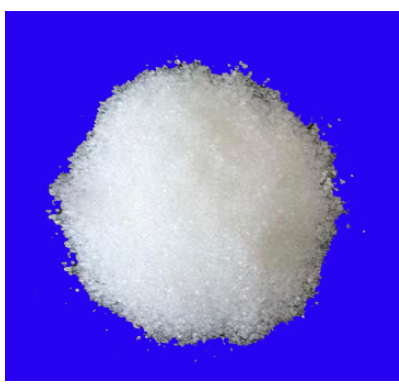

(b)

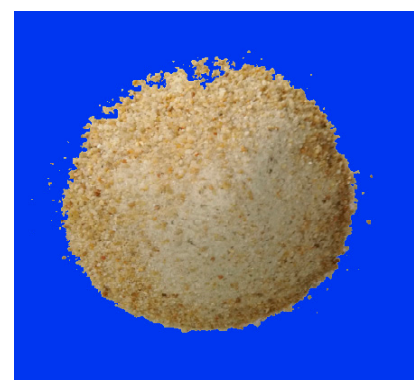

(c)

Figure 1. The raw materials: (a) Portland cement; (b) polyvinyl alcohol (PVA) power, (c) standard sand. 
The water/cement/sand ratio by weight of the specimens was selected as 0.4:1:1.5, and the PVA was incorporated at concentrations of $0 \%, 0.2 \%, 0.6 \%, 1.0 \%$, and $2.0 \%$ by weight of cement. The defoamer was added at the amount of $0.14 \%$ of cement to eliminate the entrained air bubble during the mixing process. The detailed mix design is shown in Table 4.

Table 1. Chemical composition of Portland cement.

\begin{tabular}{cccccccccc}
\hline & \multicolumn{10}{c}{ Raw Material (\%) } \\
\cline { 2 - 10 } P.O 42.5 R & $\mathrm{SiO}_{2}$ & $\mathrm{Al}_{\mathbf{2}} \mathrm{O}_{\mathbf{3}}$ & $\mathrm{CaO}$ & $\mathbf{M g O}$ & $\mathrm{Na}_{2} \mathrm{O}$ & $\mathrm{K}_{\mathbf{2}} \mathrm{O}$ & $\mathrm{Fe}_{\mathbf{2}} \mathrm{O}_{3}$ & $\mathbf{S O}_{3}$ & Loss \\
\cline { 2 - 10 } & 18.3 & 4.5 & 62.4 & 2.1 & 0.3 & 1.5 & 2.3 & 3.5 & 2.6 \\
\hline
\end{tabular}

Table 2. Physicochemical characteristics of PVA.

\begin{tabular}{cccccc}
\hline PVA-124 AR & $\begin{array}{c}\text { Molecular } \\
\text { Weight (Mw) }\end{array}$ & $\begin{array}{c}\text { Degree of } \\
\text { Hydrolysis } \\
\text { (mole \%) }\end{array}$ & PH & $\begin{array}{c}\text { Volatile } \\
\text { Content } \\
\mathbf{( \% )}\end{array}$ & $\begin{array}{c}\text { Ash Content } \\
\mathbf{( \% )}\end{array}$ \\
\cline { 2 - 6 } & 105,000 & 97 & $5 \sim 7$ & 5.0 & 0.7 \\
\hline
\end{tabular}

Table 3. Chemical composition and particle size of standard sand.

\begin{tabular}{ccccc}
\hline \multirow{2}{*}{ Standard Sand } & $\mathrm{SiO}_{2}$ Content(\%) & Mud Content(\%) & Ignition Loss(\%) & Particle Size (mm) \\
\cline { 2 - 5 } & $>96$ & $<0.2$ & $<0.4$ & $0.08 \sim 2$ \\
\hline
\end{tabular}

Table 4. Mix proportions of cement mortar.

\begin{tabular}{cccccc}
\hline \multirow{2}{*}{ Code } & \multicolumn{5}{c}{ Ratio of Material Mass to Cement Mass (\%) } \\
\cline { 2 - 6 } & Cement & Sand & Water & PVA & Defoamer \\
\hline PCM0 & 100 & 150 & 40.2 & 0 & 0.14 \\
PCM1 & 100 & 150 & 40.24 & 0.2 & 0.14 \\
PCM2 & 100 & 150 & 40.32 & 0.6 & 0.14 \\
PCM3 & 100 & 150 & 40.4 & 1.0 & 0.14 \\
PCM4 & 100 & 150 & 40.5 & 2.0 & 0.14 \\
\hline
\end{tabular}

\subsection{Sample Preparation}

PVA powder was dispersed in cold water at room temperature for $10 \mathrm{~min}$, and this mixture was heated to $95{ }^{\circ} \mathrm{C}$ with stirring to completely dissolve the PVA. Using a cement mortar mixer, cement and fine sand were first dry-mixed thoroughly for approximately three minutes. The prepared dispersed PVA solution and the remaining water were then poured into the cement mortar and mixed for two minutes with a mid speed stirring. The defoaming agent was then slowly added into the mix, and the mixing continued for three minutes with a high-speed stirring until the relatively homogeneous cement slurry was formed. The prepared mixture was poured into oiled molds and vibrated to remove air bubbles, then pouring the mixes into oiled molds $\left(40 \times 40 \times 160 \mathrm{~mm}^{3}\right)$. Afterwards, the specimens were removed from their molds after $24 \mathrm{~h}$ and cured in a moist room (relative humidity $\geq 97 \%$ ) for 28 days. The detailed process of material preparation method is shown in Figure 2. 


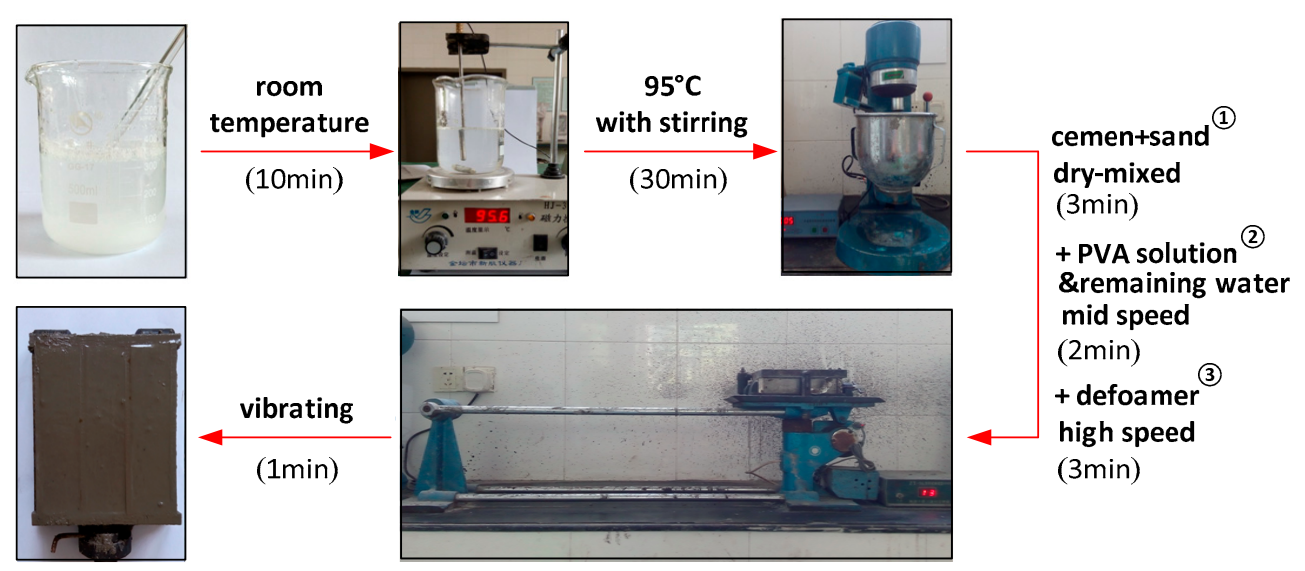

Figure 2. Illustration of the PVA modified cement mortar fabrication process.

\subsection{Testing Methods}

The flow table test was carried out on the freshly prepared mortars as described by GB/T2419-2005 [24]. The jumping table beats 25 times in $15 \mathrm{~s}$ and measures the average diameter of the fresh mortar on two mutually perpendicular sides.

The hardened density of the specimens was determined by using a water displacement method according to GB/T 11970-1997 [25].

The capillary water absorption test on cement mortar was conducted after 28-day standard curing and determined according to DIN 52617 [26]. Fifteen samples of size $40 \times 40 \times 80 \mathrm{~mm}^{3}$ were adopted in this test, and the surface of samples was wax-sealed, and then the molded surface was immersed in water, the distance between the height of the water surface and the bottom edge of the test piece was $5 \mathrm{~mm}$, the schematic diagram is shown in Figure 3. The results are the average values of three specimens.

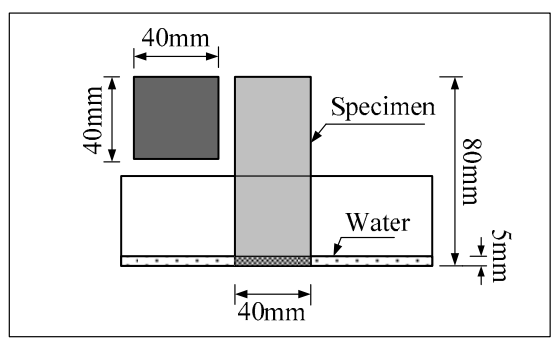

(a)

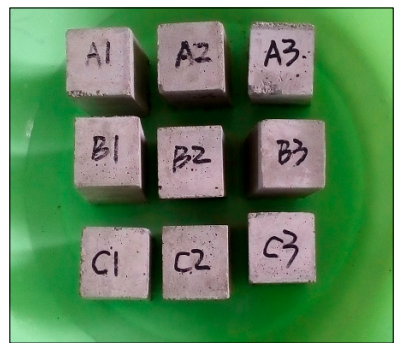

(b)

Figure 3. Capillary water absorption test schematic diagram (a) and measured diagram (b).

An electronic universal testing machine (CMT-5105, China) was used to measure flexural strength and compression strength of the composites (three samples of size $40 \times 40 \times 160 \mathrm{~mm}^{3}$ were adopted in this test). The flexural strength was tested at 3 days, 7 days, 14 days, and 28 days using a three-point method in accordance with GB/T 17671-1999 [27]. The broken pieces (portions of the prisms broken in the flexural strength test) were used to determine the cube compressive strength of the mortar samples in accordance with GB/T 17671-1999 [27].

Differential thermal analysis was using a Shimadzu DSC 50 thermal analyzer at a heating rate of $20^{\circ} \mathrm{C} / \mathrm{min}$. The samples chamber was purged with nitrogen at a flow rate of $40 \mathrm{cc} / \mathrm{min}$.

FT-IR spectra were carried out using a MAUNA-IR 750 spectrometer manufactured by Nikolai, USA. Powdered samples were mixed with $\mathrm{KBr}$ and pressed into pellets. The analyses were carried out in the frequency range of $500-4000 \mathrm{~cm}^{-1}$. 
The microstructures of the cement mortar were observed using a scanning electron microscope (SEM, SU3500) at an accelerating voltage of $10 \mathrm{kV}$. The sample was coated with a thin layer of gold before observation.

\section{Results and Analysis}

\subsection{Flow Properties}

Fluidity is an important index that reflects the working performance of a cement mortar. The flow properties of cement mortar can be evaluated by using a flow table test. Figure 4 shows the test results of the slump value of all mortars, in which the w/c ratio was fixed at 0.4 . Obviously, the incorporation of PVA greatly reduced the flow properties of mortars, as shown in Figure 4, the slump value of fresh mortars decreased from $219.4 \mathrm{~mm}$ to $108.5 \mathrm{~mm}$ with the PVA content increased from $0 \%$ to $2.0 \%$. The incorporation of $0.2 \%, 0.6 \%, 1.0 \%$ and $2.0 \%$ PVA reduced the slump value by $13.9 \%, 31.5 \%, 41.1 \%$, and $50.5 \%$, as compared to the control one, respectively. This reduction possibly attributed to the strong, cohesive force of PVA, which limits the movement of cement particles during the mixing process. Moreover, the -OH bonds in the PVA matrix may react with the -OH bonds of water, which reduce the water participating in dispersing of cement particles. The working performance impacts the mechanical properties of cement mortar, and generally, a higher slump value leads to a better uniformity for the fresh mortar, which further results in a higher mechanical properties. Thus, the content of PVA for actual engineering applications should be as small as possible.
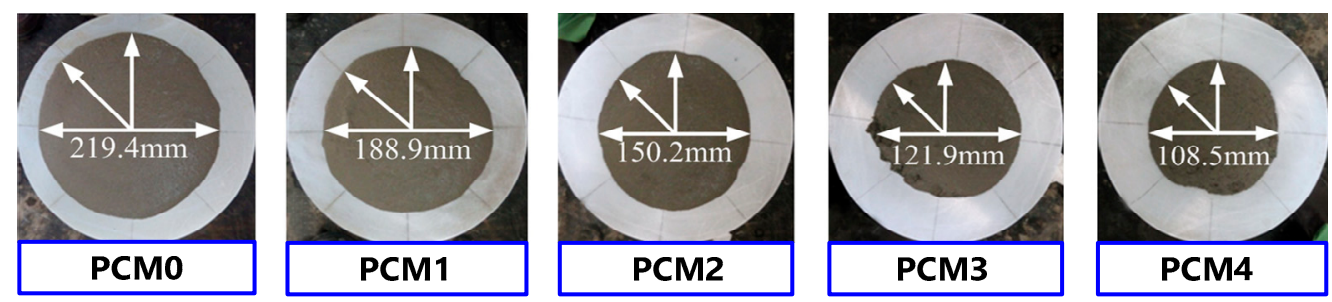

Figure 4. Effect of PVA content on the flow spread diameter of fresh mortar mixes.

\subsection{Flexural Strength}

Figure 5 shows the flexural strength of cement mortars with 0.2 2.0\% PVA after 3 28 days of curing. Clearly, the flexural strength of mortars increased at first and then decreased with the increase of PVA content. PCM3 containing 1.0\% PVA shows the highest flexural strength. The 7-day, 14-day and 28-day flexural strengths were about $31.9 \%, 28.8 \%$ and $24.8 \%$ higher than those of the control mixture without PVA. In addition, the curing ages also impacted the flexural strength development, which generally increased with the increase of curing age. However, the increasing rate was greatly influenced by the PVA content. When the PVA content was $0 \sim 0.6 \%$, the increasing rate of flexural strength for different samples was very similar. However, when incorporating 1.0 2.0 wt. \% PVA, the flexural strength slightly increased with the increase of curing ages. The 28-day flexural strength of PCM4 containing 2.0\% PVA was just $12.5 \%$ higher than the three-day flexural strength, while for PCM2, the flexural strength after 28 days of curing was about $29.0 \%$ higher than that after three days of curing. 


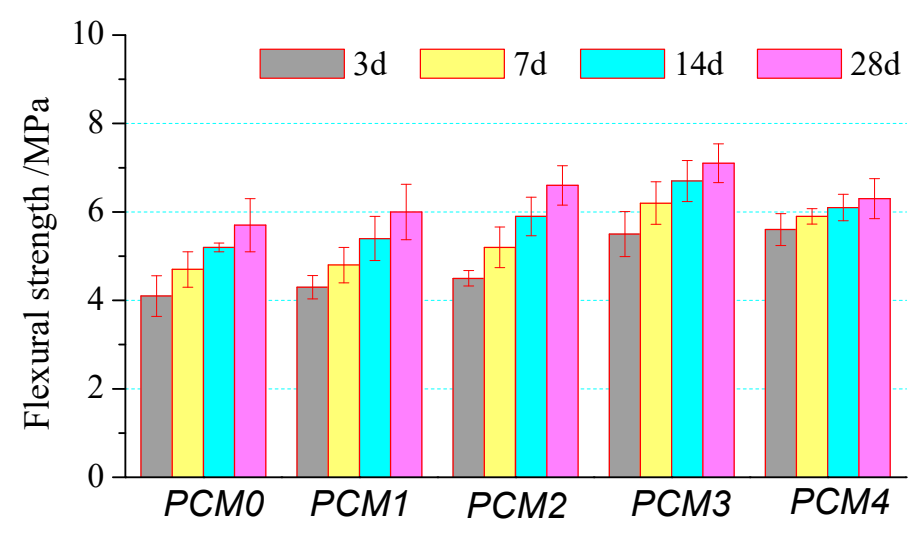

Figure 5. Effects of PVA content on the flexural strength of cement mortar.

\subsection{Compressive Strength}

Figure 6 shows the compressive strength development of cement mortars with 0 2.0\% PVA at the early age. Clearly, the growth trend of compressive strength of all mortars was quite similar to that of flexural strength, in which the strength increased at first and then decreased with the increase of PVA content. However, Figure 6 shows that the optimal use of PVA was $0.6 \%$ of cement content by mass, and the compressive strength increased by $12.15 \%$ as compared to PCM0 after 28 days of curing. Moreover, it is worth noting that the curing age impacted the improvement effect of PVA, and the reinforcement effect was more remarkable at the early curing age. For example, the three-day compressive strength of PCM2 was about 17.6\% higher than that of PCM0, while its 14-day strength just increased by $14.9 \%$, as compared to PCM0. Additionally, the excessive adding of PVA might reduce the compressive strength. As shown in Figure 6, the 28-day compressive strengths of PCM4 were about $5.5 \%$ lower than those of PCM0.

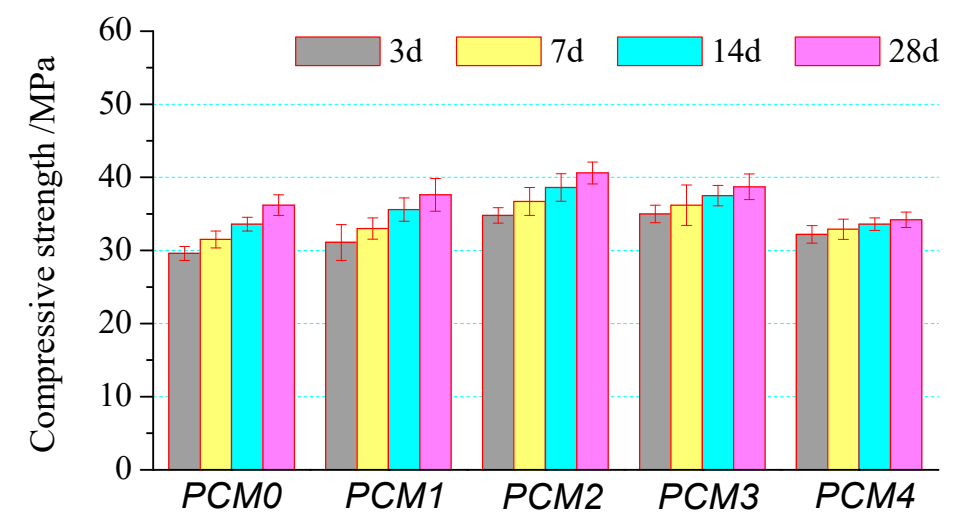

Figure 6. Effects of PVA content on the compressive strength of cement mortar.

\subsection{Volume Density}

The mass per unit volume of a material that contains open and closed pores is referred to as the volume density, and the volume density can reflect the degree of internal compactness of materials. Figure 7 shows the effect of the PVA content on the volume density of the cement mortar. For the measured value, the volume density of the mortar increased with increasing PVA content until it reached an optimal amount of approximately $0.6 \mathrm{wt}$. \%, and then started to decrease. This indicates that the incorporation of a proper amount of PVA can improve the internal pore structure of the mortar and improve the compactness of the mortar. The maximum density of $2148.8 \mathrm{~kg} / \mathrm{m}^{3}$ corresponded to $0.6 \%$ PVA and compared with the mortar without PVA $\left(2028.5 \mathrm{~kg} / \mathrm{m}^{3}\right)$, the increase in the density was determined to be $5.9 \%$. When the PVA content continued to increase, it was difficult to uniformly mix the mortar during the stirring and shaking process due to its poor working performance, so the 
internal pores increased, and the volume density decreased. The minimum density of $1992.1 \mathrm{~kg} / \mathrm{m}^{3}$ corresponded to $2.0 \%$ PVA content.

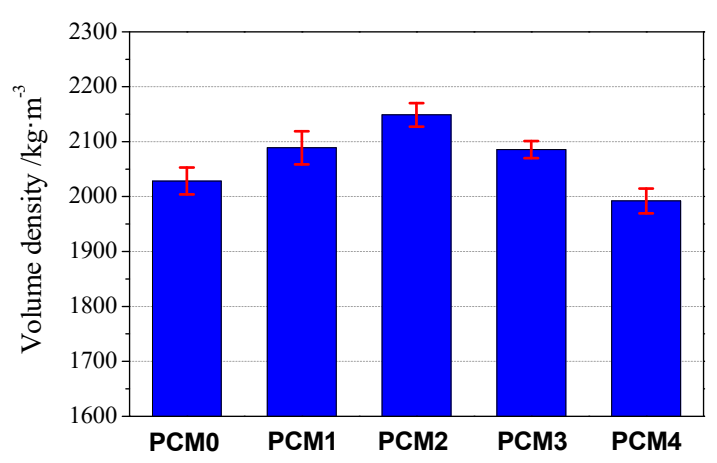

Figure 7. Effects of PVA content on the volume density of cement mortar.

\subsection{Capillary Water Absorption}

The water absorption of a material depends not only on its hydrophily but also on its porosity and pore size distribution. Figure 8 shows the capillary water absorption of cement mortars containing $0.2 \sim 2.0 \%$ PVA. The capillary water absorption rate is plotted on the ordinate, and the square root of time $\mathrm{t}^{0.5}$ is the abscissa. By analyzing the relationship between the capillary water absorption and the square root of the time, the pore characteristics of the mortar can be reflected. According to the test results in the figure, it can be found that the curve shape of water absorption of cement mortars with or without PVA was quite similar, and which can be divided into two stages: A rapid ascending phase (stage I), and a steady phase (stage II). At stage I, water diffuse along the micro-cracks or interconnecting holes and then fill the pores of surrounding mortar. Thus, the more micro-cracks and interconnecting holes, the faster this stage will ascend. Clearly, according to Figure 8, PCM0 had the highest micro-cracks or interconnecting holes, followed by PCM4, and PCM2 had the lowest micro-cracks and interconnecting holes as its ascending rate was the lowest. In stage II, the pores were filled by water to a certain level, the equilibrium between the rates of transporting moisture and filling pores is built. At this stage, the capillary water absorption value is related to the porosity, and a higher water absorption value means a higher porosity. The effect of PVA on the water absorption of mortar may be because (1) PVA reduces the hydrophily, and (2) PVA film fills the pores of the cement matrix. For this reason, the samples containing PVA had a much lower absorption over the control one. Especially for PCM2, the capillary water absorption of cement mortar was the lowest value of $3.21 \mathrm{~kg} / \mathrm{m}^{2}$, which was $60 \%$ lower than that of PCM0. However, it should be noted that the addition of PVA will reduce the flow properties of cement mortar, as shown in Figure 4, the higher the PVA content, the lower the slump value was. Particularly for PCM4, the slump value reduced by about $50 \%$ as compared to PCM0. The poor flow behavior might cause the uneven dispersion of cement mortar, consequently, the interconnecting holes probably increased with the increase of PVA. 


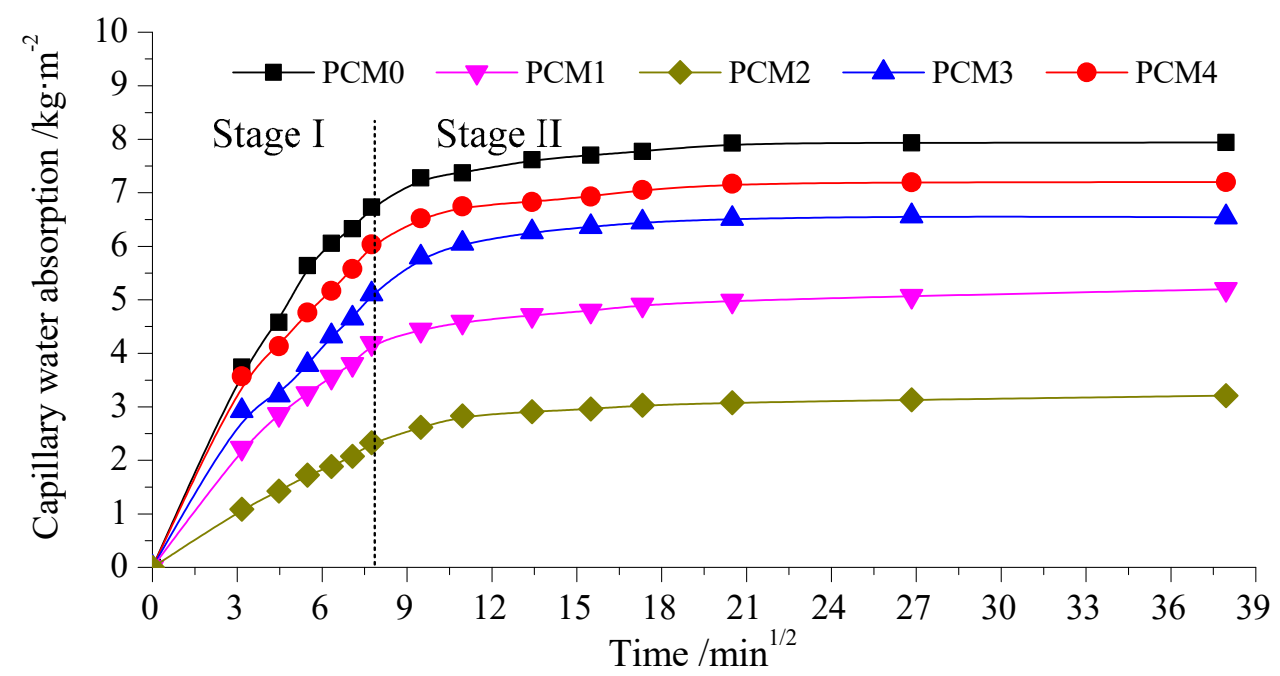

Figure 8. Capillary water absorption of cement mortar with different PVA contents $(0 \sim 24 \mathrm{~h})$.

\subsection{Thermal Analysis}

The above-mentioned test results indicate that the adding of $0.6 \%$ PVA had a considerable effect on increasing the mechanical property and reducing the water absorption of cement mortar, while the excessive incorporation of $2.0 \%$ PVA hardly affected the properties of cement mortar. To understand the mechanism behind these opposite levels of effectiveness of PVA on cement mortar, the microstructure of cement mortar incorporating of $0.6 \%$ and $2.0 \%$ PVA was studied, for comparison, the property of cement mortar without PVA was also investigated.

Firstly, the thermal decomposition performance of cement mortars containing $0 \%, 0.6 \%$, and 2.0\% PVA was investigated by using differential scanning thermal analysis (DSC), and the results are shown in Figure 9a. There are two major endothermic peaks in the three curves, as shown in Figure 9a. The first endoscopic endothermic peak is located at $95{ }^{\circ} \mathrm{C}$, which is caused by the evaporation of adsorbed water. The second endoscopic endothermic peak is located at $430 \sim 450{ }^{\circ} \mathrm{C}$, which is caused by the decomposition of $\mathrm{Ca}(\mathrm{OH})_{2}$. The two absorption peaks of the three curves are integrated in Figure $9 \mathrm{~b}$ to assess the effect of PVA on the thermal decomposition of cement mortar. Comparing the first endothermic peaks of all DSC curves, it can be found that PCM0 without PVA is $18.245 \mathrm{~J} / \mathrm{g}$, and the incorporating $0.6 \%$ PVA increased the endothermic enthalpy values by $13.8 \%$. However, the adding of $2.0 \%$ PVA reduced the first absorption peak by $9.3 \%$ as compared to PCM0 without PVA. This result indicates that the incorporation of $0.6 \%$ PVA might accelerate the hydration rate of the cement matrix, while the addition of $2.0 \%$ of PVA delay the hydration rate. Comparing the second absorption peak of the three samples, it can be found that PCM0 had the highest value of $22.145 \mathrm{~J} / \mathrm{g}$, followed by PCM2 having a peak value of $19.51 \mathrm{~J} / \mathrm{g}$, and PCM4 had the lowest value of $17.243 \mathrm{~J} / \mathrm{g}$. Figure $9 \mathrm{~b}$ shows that the first endothermic peak corresponds to the evaporation of adsorbed and interlayer water of PCM2 was much higher than that of PCM0, while the second peak corresponds to the decomposition of $\mathrm{Ca}(\mathrm{OH})_{2}$. This conflicting result may be due to the -OH bonds in PVA chain react with the -OH bonds of $\mathrm{Ca}(\mathrm{OH})_{2}$, leading to the reduction of the content of $\mathrm{Ca}(\mathrm{OH})_{2}$, which is further studied by using FTIR and reported in the next section. 


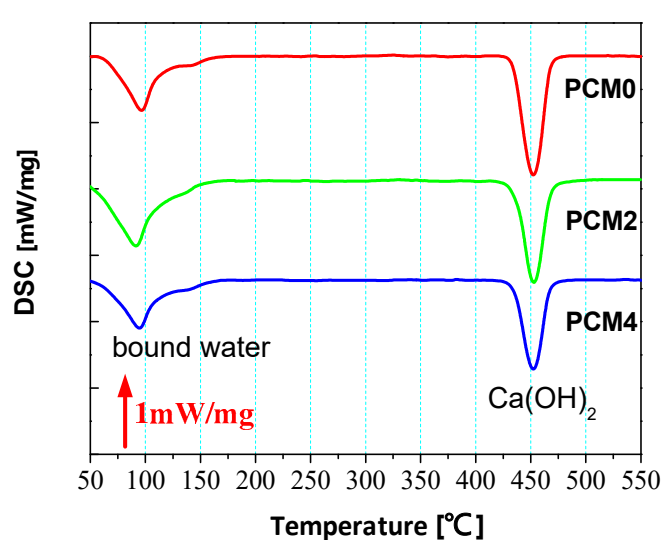

(a)

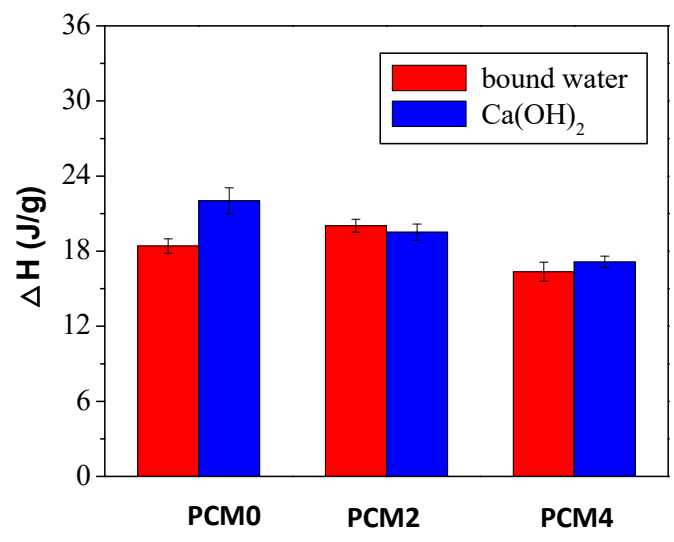

(b)

Figure 9. Differential scanning calorimetry (DSC) analysis of cement mortars at 28 days. (a) DSC curves and $(\mathbf{b})$ bound water and $\mathrm{Ca}(\mathrm{OH})_{2}$ content.

\subsection{FTIR Spectroscopy}

The FTIR analyses of cement mortar containing $0.6 \%$ and $2.0 \%$ PVA were conducted after 28 days of curing, and the spectra are shown in Figure 10 for comparison. As shown in Figure 10, all curves have obvious characteristic peaks at $3643,1643,1452$, and $973 \mathrm{~cm}^{-1}$. The absorption peak near $3643 \mathrm{~cm}^{-1}$ corresponds to the characteristic peak of free hydroxyl in the $\mathrm{Ca}(\mathrm{OH})_{2}$ molecule produced by cement hydration. The characteristic absorption peak of $\mathrm{Si}-\mathrm{O}$ of $\mathrm{C}-\mathrm{S}-\mathrm{H}$ of cement hydration products is at near $973 \mathrm{~cm}^{-1}$. The peak at $1452 \mathrm{~cm}^{-1}$ corresponds to the stretching of $\mathrm{CaCO}_{3}$. The FTIR spectra of PCM2 containing $0.6 \%$ PVA shows more intense absorption peaks at $973 \mathrm{~cm}^{-1}$ as compared to $\mathrm{CM}$, indicating the positive effect of PVA on accelerating the hydration rate of the cement matrix. However, this peak of PCM4 was much lower than that of PCM0, indicating the excessive addition of PVA impacted the hydration of the cement matrix in a negative way. Moreover, Figure 10 shows that the addition of PVA reduced the spectral data at $3643 \mathrm{~cm}^{-1}$, which corresponds to the $-\mathrm{OH}$ band of $\mathrm{Ca}(\mathrm{OH})_{2}$. This result coincides well with the results of DSC.

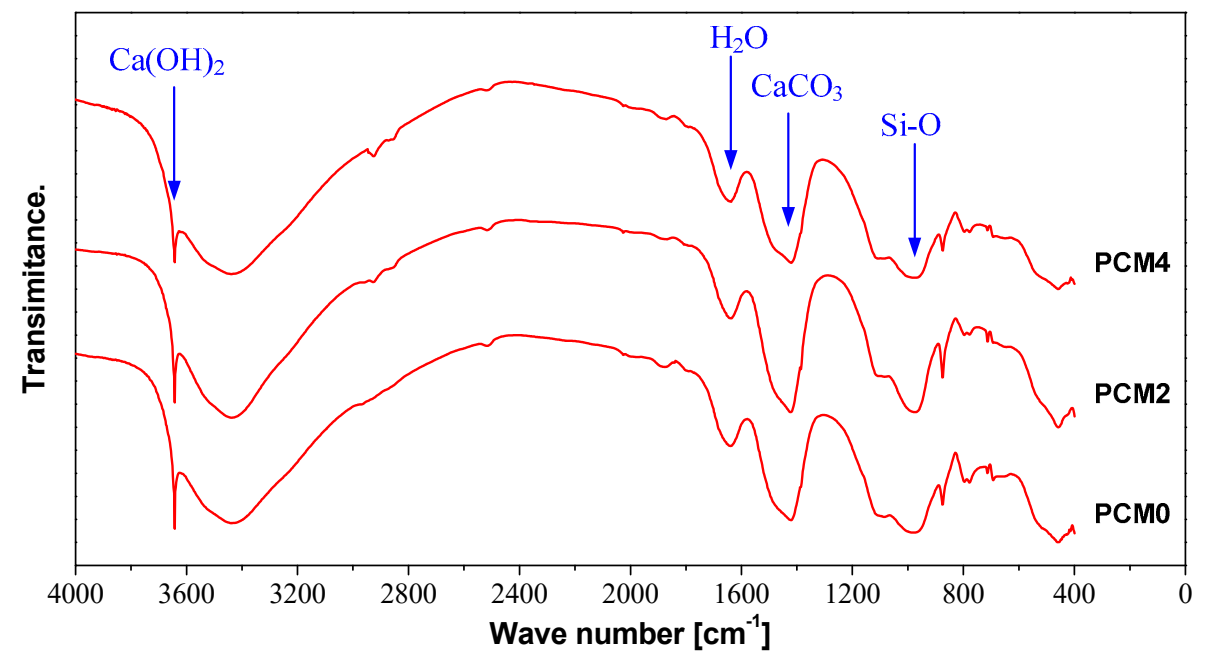

Figure 10. Fourier transform infrared spectroscopy (FTIR) analysis of cement mortar with different PVA content. 


\subsection{SEM Investigation}

Scanning electron microscopy is an important means of analyzing the internal microstructure of materials. Scanning electron microscopy images can be used to determine the composition of the pore structure inside the cement matrix, the internal shape of the cement matrix and the type of hydration products. Figure 11 shows the microstructure of the modified mortar with a PVA content of $0.6 \%$ for 28 days of curing. As shown in Figure 11, the internal structure, pore distribution, and pore size composition of the modified mortar changed with the incorporation of PVA. The polymer was evenly distributed in the cement matrix while the cement mortar was being agitated and intertwined with the cement hydration product. As the cement hydration reaction progressed, the polymer continuously precipitated in the cement to form a polymer film. The presence of these films can play the following roles: (1) The films can combine with the hydration product to enhance the connection between the hydration products, thereby improving the mechanical properties of the cement mortar. (2) Part of the film can become interspersed with the cement base. Between the pores, it can fill the pores and form bridges in the cement plate. Under a load, it can absorb the energy generated by the external force so that the mechanical properties of the cement matrix are improved [23]. (3) The presence of the polymer can refine the pores, making a large number of harmful pores decrease into medium-sized or even harmless pores, thereby enhancing the mechanical properties of the cement mortar. In addition, it can be clearly observed in Figure 11 that the polymer film spans the crack between the cement plates to form a load transfer bridge. Under the action of an external force, the film is torn, and the energy generated by the external load is absorbed so that the crack generation and development process of the cement plate are delayed.
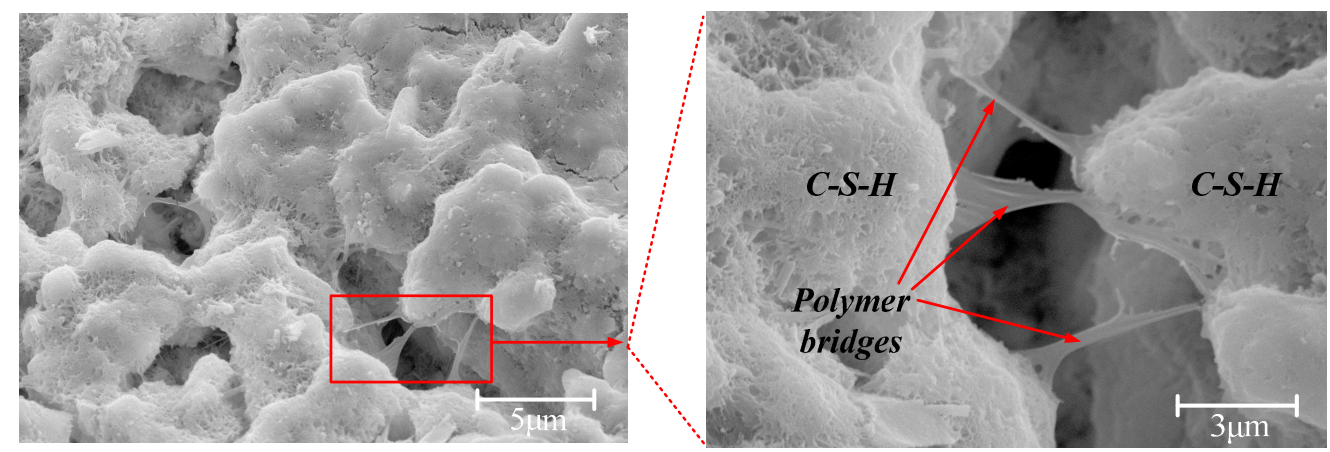

Figure 11. Polymer film stretched in open space in $0.6 \%$ PVA modified mortar at 28 days.

Figure 12 shows the microstructure of the modified mortar with a PVA content of $1.0 \%$. As shown in Figure 12, as the amount of PVA increased, polymer film combines with the hydration product in the cement matrix to form a stable continuous network-like structure. This structure improves the mechanical properties of the mortar, especially the bending performance.
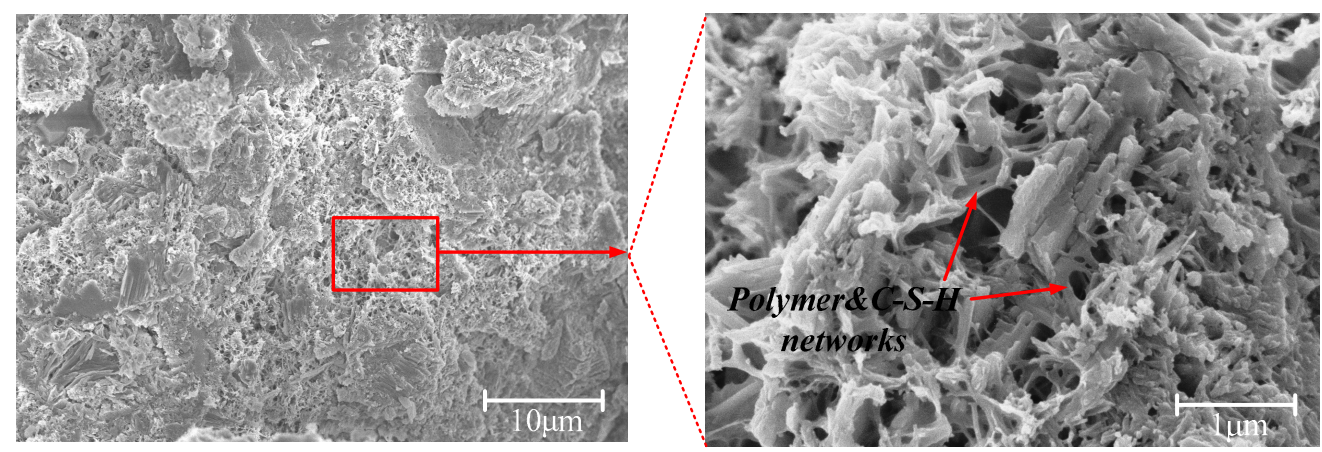

Figure 12. Network-like structure in cement mortar with the PVA content of $1.0 \%$ at 28 days. 
Figure 13 is the SEM image of PCM4 containing 2.0\% PVA. Figure 13 shows that the morphology and microstructure of PCM4 are quite different from PCM2. The excessive incorporation of PVA led to the formation of heave polymer sheets within the cement matrix. These heavy PVA film might coat cement particles and prevent them from having contact with water. This coated effect of PVA might delay the hydration rate of cement, as demonstrated by DSC and FTIR test results as shown in Figures 9 and 10. The lower compressive strength of PCM4 over PCM0 might be due to its lower hydration rate caused by the coated effect of PVA. In addition, Figure 13 shows the positive effect of PVA on bridging cracks, which lead to the increase of flexural strength of mortar as shown in Figure 6, where the three-day flexural strength of PCM4 was about $36.6 \%$ and $1.8 \%$ higher than that of PCM0 and PCM2, respectively.
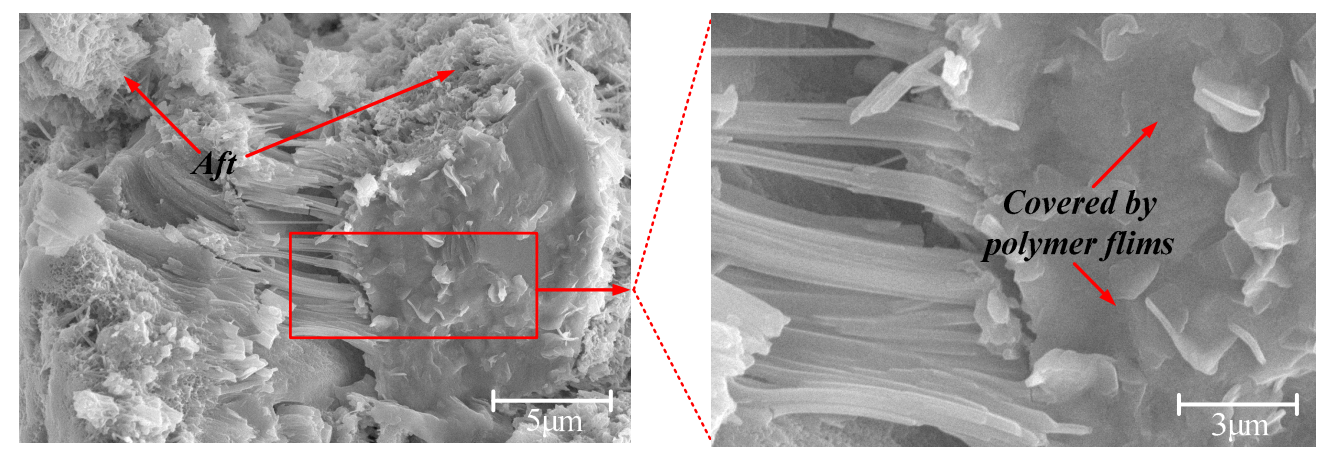

Figure 13. SEM image of cement mortar with $2.0 \%$ PVA content at 28 days.

The results of the scanning electron microscopy analysis show the following: (a) The proper amount of PVA incorporation $(0.6 \% \sim 1.0 \%)$ can be evenly distributed inside the matrix with an appropriate aggregate stirring process. A uniformly distributed polymer film can be formed that has a certain tensile strength. The polymer film bridging between the cement plates can delay or inhibit crack development of the cement mortar. Additionally, the film also can combine with hydration products to form a network-like structure. The structural system improves the mechanical properties of the cement mortar, especially for the flexural strength. (b) When the PVA content is too high (2.0\%), the mortar has a poor working performance, and it is difficult to stir evenly. The incorporation of a large amount of PVA forms an uneven distribution inside the matrix. The cement curing process leads to the formation of a large and thick polymer film that coats the surface of the cement particles and hinders the hydration of the cement, thereby reducing the mechanical properties of the cement mortar.

\section{Conclusions}

This study investigated the strength development of cement mortars at the early age ( $3 \sim 28$ days) after loading various polyvinyl alcohol (PVA) contents to obtain an optimum proportion. Then, the microstructure and morphology of PVA-modified cement mortar were studied by using DSC and FTIR to reveal its working mechanism. According to the test results in this study, the main achievements were:

(1) PVA has a strong cohesiveness and water retention, and its incorporation reduces the fluidity of cement mortar. The incorporation of $0.2 \%, 0.6 \%, 1.0 \%$, and $2.0 \%$ PVA reduced the slump value by $13.9 \%, 31.5 \%, 41.1 \%$, and $50.5 \%$ as compared to the control one, respectively.

(2) The mechanical properties of cement mortar show a significant increase at first and then decrease with the increase of PVA content. Cement mortar containing 0.6\% PVA has the highest compressive strength, its 28 -day compressive strength is $12.1 \%$ higher than that of the control one. The incorporating 1.0\% PVA increased the flexural strength greatly, its 28-day flexural strength is about $24.8 \%$ higher than that of the control one. 
(3) The bulk density and water absorption test results show that the incorporation of $0.6 \%$ PVA increases the bulk density of cement mortar by $5.90 \%$, and the corresponding capillary water absorption decreases by $60 \%$ as compared to the control mortar, respectively.

(4) SEM tests show that three-dimensional PVA networks are formed in cement mortar. The crack-bridging effect of PVA film can be observed in the SEM images. When 2.0\% PVA was incorporated, PVA formed heavy films, coating cement particles and preventing them from hydration.

(5) DCS and FTIR analyses results manifest the adding of $0.6 \%$ PVA accelerates the hydration of the cement matrix, while the incorporation of $2.0 \%$ PVA impacts the hydration rate of cement in a negative way.

Author Contributions: Conceptualization, J.F. and G.L.; data curation, S.D. and Z.W.; writing of the original draft, J.F. and Z.W; writing of review and editing, G.L.

Funding: This work is supported by the National Natural Science Foundation of PR China (No. 51708145, No. 51878299), the project of Natural Science Research Foundation of Guizhou Province (No. [2018]1064), and the Science and Technology Plan of Guangdong Province (2015A010105029).

Acknowledgments: This work is supported by the National Natural Science Foundation of PR China (No. 51708145, No. 51878299), the project of Natural Science Research Foundation of Guizhou Province (No. [2018]1064), and the Science and Technology Plan of Guangdong Province (2015A010105029). The authors are grateful for the above supporters.

Conflicts of Interest: The authors declare no conflict of interest.

\section{References}

1. Luo, Z.; Li, W.; Wang, K.; Shah, S.P. Research progress in advanced nanomechanical characterization of cement-based materials. Cem. Concr. Compos. 2018, 94, 277-295. [CrossRef]

2. Sang, G.; Zhu, Y.; Yang, G. Mechanical properties of high porosity cement-based foam materials modified by EVA. Constr. Build. Mater. 2016, 112, 648-653. [CrossRef]

3. Yang, H.; Cui, H.; Tang, W.; Li, Z.; Han, N.; Xing, F. A critical review on research progress of graphene/cement-based composites. Compos. Part A Appl. Sci. Manuf. 2017, 102, 273-296. [CrossRef]

4. Ohama, Y. Handbook of Polymer-Modified Concrete and Mortars; Noyes Publications: Park Ridge, NJ, USA, 1995.

5. Sakai, E.; Sugita, J. Composite mechanism of polymer modified cement. Cem. Concr. Res. 1995, 25, 127-135. [CrossRef]

6. Park, D.; Ahn, J.; Oh, S.; Song, H.; Noguchi, T. Drying effect of polymer-modified cement for patch-repaired mortar on constraint stress. Constr. Build. Mater. 2009, 23, 434-447. [CrossRef]

7. Li, G.; Zhao, X.; Rong, C.; Wang, Z. Properties of polymer modified steel fiber-reinforced cement concretes. Constr. Build. Mater. 2010, 24, 1201-1206. [CrossRef]

8. Mirza, J.; Mirza, M.S.; Lapointe, R. Laboratory and field performance of polymer-modified cement-based repair mortars in cold climates. Constr. Build. Mater. 2002, 16, 365-374. [CrossRef]

9. Assaad, J.J. Development and use of polymer-modified cement for adhesive and repair applications. Constr. Build. Mater. 2018, 163, 139-148. [CrossRef]

10. Shaker, F.A.; El-Dieb, A.S.; Reda, M.M. Durability of Styrene Butadiene latexmodified concrete. Cem. Concr. Res. 1997, 27, 711-720. [CrossRef]

11. Almeida, A.E.D.S.; Sichieri, E.P. Mineralogical study of polymer modified mortar with silica fume. Constr. Build. Mater. 2006, 20, 882-887. [CrossRef]

12. Xu, F.; Zhou, M.; Chen, J.; Ruan, S. Mechanical performance evaluation of polyester fiber and SBR latex compound-modified cement concrete road overlay material. Constr. Build. Mater. 2014, 63, 142-149. [CrossRef]

13. Yahya, G.O.; Ali, S.A.; Al-Naafa, M.A.; Hamad, E.Z. Preparation and viscosity behavior of hydrophobically modified poly(vinyl alcohol) (PVA). J. Appl. Polym. Sci. 2010, 57, 343-352. [CrossRef]

14. Rim, I.W.; Robertson, R.E.; Robert, Z. Effects of Some Nonionic Polymeric Additives on the Crystallization of Calcium Carbonate. Cryst. Growth Des. 2005, 5, 513-522. 
15. Wang, S.; Ren, J.; Li, W.; Sun, R.; Liu, S. Properties of polyvinyl alcohol/xylan composite films with citric acid. Carbohydr. Polym. 2014, 103, 94-99. [CrossRef]

16. Sahoo, S.K.; Panyam, J.; Prabha, S.; Labhasetwar, V. Residual polyvinyl alcohol associated with poly (D,L-lactide-co-glycolide) nanoparticles affects their physical properties and cellular uptake. J. Control. Release 2002, 82, 105-114. [CrossRef]

17. Zhang, Y.; Ye, L.; Cui, M.; Yang, B.; Li, J.; Sun, H.; Yao, F. Physically crosslinked poly(vinyl alcohol)-carrageenan composite hydrogels: Pore structure stability and cell adhesive ability. RSC Adv. 2015, 5, 78180-78191. [CrossRef]

18. Chopra, P.; Nayak, D.; Nanda, A.; Ashe, S.; Rauta, P.R.; Nayak, B. Fabrication of poly(vinyl alcohol)-Carrageenan scaffolds for cryopreservation: Effect of composition on cell viability. Carbohydr. Polym. 2016, 147, 509-516. [CrossRef]

19. Ma, Y.; Bai, T.; Wang, F. The physical and chemical properties of the polyvinylalcohol/ polyvinyl-pyrrolidone/hydroxyapatite composite hydrogel. Mater. Sci. Eng. C Mater. Biol. Appl. 2016, 59, 948. [CrossRef]

20. Zheng, Y.; Huang, X.; Wang, Y.; Xu, H.; Chen, X. Performance and characterization of irradiated poly(vinyl alcohol)/polyvinylpyrrolidone composite hydrogels used as cartilages replacement. J. Appl. Polym. Sci. 2009, 113, 736-741. [CrossRef]

21. Singh, N.B.; Rai, S. Effect of polyvinyl alcohol on the hydration of cement with rice husk ash. Cem. Concr. Res. 2001, 31, 239-243. [CrossRef]

22. Knapen, E.; Van Gemert, D. Polymer film formation in cement mortars modified with water-soluble polymers. Cem. Concr. Compos. 2015, 58, 23-28. [CrossRef]

23. Kim, J.H.; Robertson, R.E. Effects of Polyvinyl Alcohol on Aggregate-Paste Bond Strength and the Interfacial Transition Zone. Adv. Cem. Based Mater. 1998, 8, 66-76. [CrossRef]

24. Test Method for Fluidity of Cement Mortar, China; GB/T 2419-2005; Architecture \& Building Press: Beijing, China, 2005. (In Chinese)

25. Test Methods for Bulk Density, Moisture and Water Absorption of Aerated Concrete, China; GB/T 11970-1997; Architecture \& Building Press: Beijing, China, 1997. (In Chinese)

26. Determination of The Water Absorption Coefficient of Construction Materials; DIN 52617; German Institute for Standardisation: Berlin, Germany, 1987.

27. Method of Testing Cements-Determination of Strength, China; GB/T 17671-1999; Architecture and Building Press: Beijing, China, 2003. (In Chinese) 